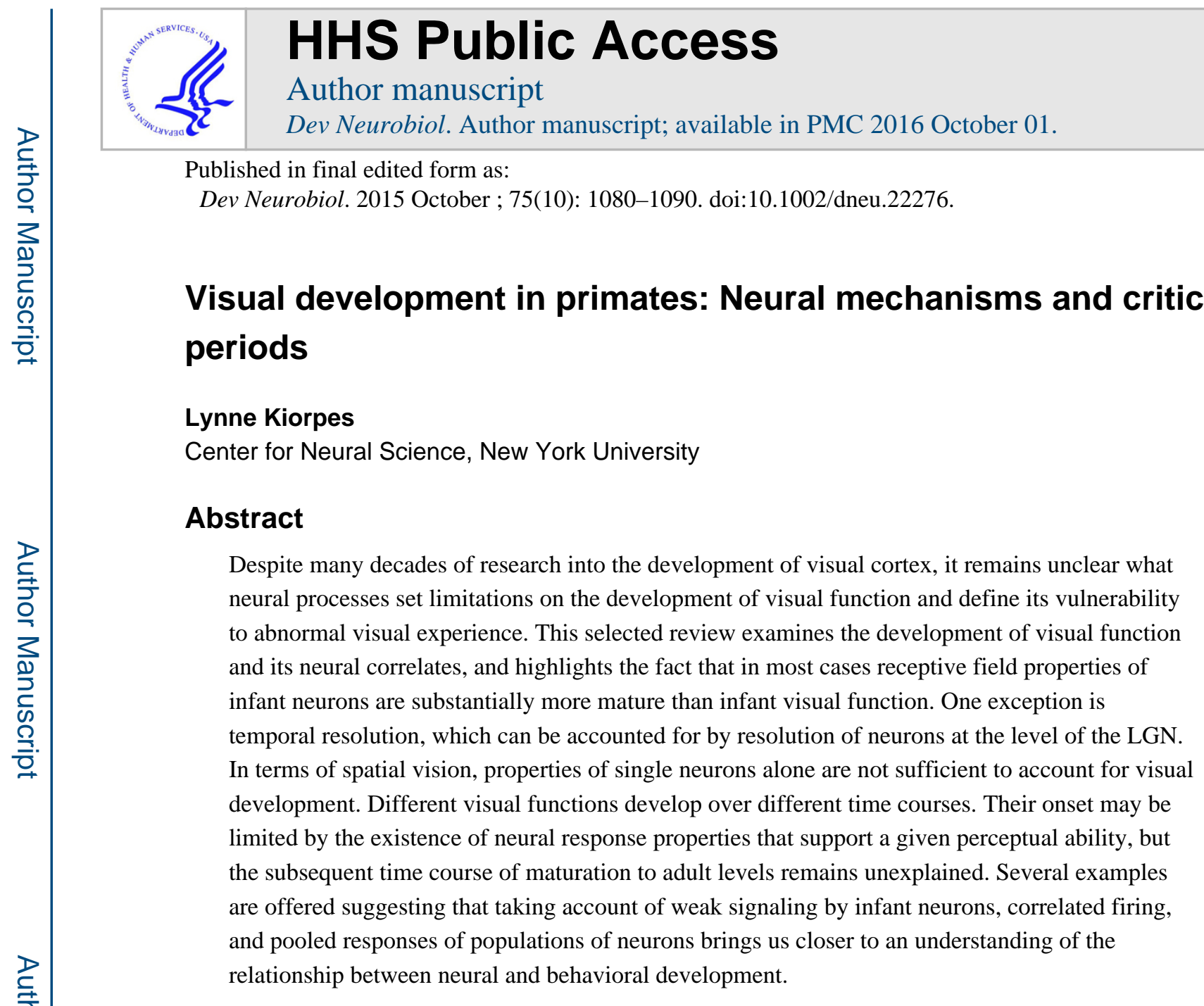

\title{
Keywords
}

Visual development; visual cortex; critical period; extrastriate cortex

In the 1960's, Wiesel and Hubel brought to light the dramatic effects of visual experience on the postnatal development of the visual system of kittens (Wiesel \& Hubel, 1963; 1965) and later macaque monkeys (Hubel, Wiesel \& LeVay, 1977; LeVay, Wiesel \& Hubel, 1980; Wiesel, 1982). The succeeding 50 years brought countless studies delving into the requirements for and limitations on such plasticity, and documentation of the period of vulnerability of the visual cortex. One of the important concepts to emerge from their groundbreaking work was that of the 'critical period' for visual cortex and the findings that normal visual experience was necessary to maintain species-typical cortical development (see Movshon \& Kiorpes, 1990; Kiorpes \& Movshon, 2004a). Wiesel and Hubel's insight was based on a disruption of the binocular organization they had discovered - coined 'ocular dominance' - in primary visual cortical area V1. They showed that closing one eye during an early postnatal period resulted in a dramatic loss of influence of that eye over neurons in

Lynne Kiorpes, Center for Neural Science, New York University, 4 Washington Place, New York, NY 10003, Tel: 212-998-7780, Fax: 212-995-4011, kiorpes@nyu.edu.

The author has no conflict of interest to declare. 
$\mathrm{V} 1$ and a reduction in the number of neurons that retained inputs from both eyes. The older the organism was at the time of deprivation or the shorter the duration of the deprivation, the less dramatic the ocular dominance deficits. Using ocular dominance as an assay, it was possible to essentially map out critical period plasticity over time and show that the highest sensitivity to manipulation was within the early postnatal months in primates, with a steady decline thereafter until no further effect was found.

Another important concept to emerge from the work of Wiesel, Hubel and their colleagues was that the concept of $a$ critical period for cortical development was something of a misnomer. In fact, using the identical manipulation in the same visual area they identified multiple critical periods. Different metrics for ocular dominance - physiological versus anatomical - as well as different cell types and layers revealed not one but multiple critical periods, with different levels within V1 showing slightly different periods of vulnerability (see Hubel, Wiesel \& LeVay, 1977; LeVay, Wiesel \& Hubel, 1980). For example, Layer IV neurons were susceptible to ocular dominance modification for a shorter period of time than those in upper layers $2 / 3$, and physiologically assayed properties showed longer periods of plasticity than anatomical ones (see also, Horton \& Hocking, 1997). The physiological pattern of plasticity clearly seemed to result from interocular competition at the site of typically binocular neurons in V1. No such plasticity was found following even long-term deprivation at the level of the LGN - the immediately earlier level of the visual system and the major source of input to V1 (Blakemore \& Vital-Durand, 1986; Levitt et al., 2001). Although there was anatomical evidence of degeneration and shrinkage of neurons in deprived eye laminae of the LGN (e.g., Headon et al., 1979), there were only minimal physiological manifestations of the deprivation. Thus the primary ocular dominance effects first described by Wiesel and colleagues arose de novo at the level of V1. These and other demonstrations of developmental plasticity in $\mathrm{V} 1$ led to the strong and enduring conclusion that striate cortex was the site of important neural correlates of visual development. However, from more recent investigations there emerged indications to the contrary.

Among the earliest evidence that the progress of visual development in primates might not be limited by neural development at the level of V1 was a report by Harwerth and colleagues $(1986 ; 1990)$ showing that monocular deprivation had different degrees of influence on various behavioral measures of visual function and that the critical periods for those measures were quite different. For example, deprivation affected the development of luminance and chromatic sensitivity only during the first 3 to 6 months after birth, while spatial modulation and high spatial frequency sensitivity could be modified over 1-2 years. Figure 1A shows the dramatic effects of monocular deprivation by lid-suture beginning a few months after birth, while Figure 1B shows the comparatively mild results of the same deprivation beginning at 1 year of age. Binocular summation, a measure of coordinated activity of the two eyes showed the longest critical period. These effects of deprivation documented behaviorally were apparent well beyond the approximately 3-6 month time period previously demonstrated even for physiological plasticity in area V1.

The first direct comparison of physiological, anatomical and behavioral development in individual primate infants came in a series of experiments employing a less dramatic form of visual deprivation, unilateral atropinization, during development (Kiorpes et al., 1987; 
Movshon et al., 1987; Hendrickson et al., 1987). While monocular deprivation permits only light exposure without form vision through the closed eyelid, atropinization permits spatial visual experience albeit degraded by blur resulting from paralysis of accommodation by daily instillation of atropine. This treatment is a model for amblyopia, a developmental vision disorder that occurs naturally in about $3 \%$ of young children. Infant monkeys were raised with unilateral blur from chronic treatment with atropine to one eye beginning shortly after birth; the loss of spatial vision - acuity and contrast sensitivity - that resulted from the special rearing was documented behaviorally (see Fig. 1C; Kiorpes et al., 1987). Anatomical and neurophysiological investigations of LGN and V1 were conducted in the same animals once the rearing period was over. The LGN, as in monocular deprivation, was relatively unaffected, with some anatomical degradation seen in deprived-eye layers but no physiological difference between the response properties of neurons recorded in deprived and non-deprived eye layers. However, the pattern of atropine-rearing effects in striate cortex was quite different. Anatomical correlates, as assayed by cytochrome oxidase staining (CO), revealed an abnormal banding pattern in Layer IV (Hendrickson et al., 1987) while physiological assessment of ocular dominance did not show a shift away from the treated eye in Layer IV. Outside Layer IV, neurons driven by the treated eye showed altered spatial tuning properties - reduced spatial frequency preference and contrast sensitivity - and, in cases of severe vision loss, a reduction in influence of the treated eye in cortex (Movshon et al., 1987). The results of this experimental series called into question the simple notion that ocular dominance effects in V1 accounted for the loss of vision following early abnormal visual experience, especially in cases of comparatively mild visual deficits as are more typical of humans with amblyopia. Subsequent studies confirmed the finding that the depth of amblyopic deficits from early unilateral blur and another commonly occurring condition: strabismus (ocular misalignment that can cause amblyopia during childhood; Fig. 1D), is not closely linked to ocular dominance shifts in V1 and that deficits in some monocular receptive field properties may be more predictive of the vision loss (Kiorpes et al., 1998; Kiorpes \& Movshon, 2004a). However, a few other studies have reported that even monocular receptive field properties in V1 are largely normal despite vision loss following early strabismus (Smith et al., 1997; Sakai et al., 2006; Bi et al., 2011). Whatever the case, an ocular dominance imbalance - as hypothesized based on Wiesel and Hubel's early work - does not appear to directly determine the existence or extent of vision loss that results from early abnormal visual experience. Furthermore, ocular dominance plasticity does not define the critical period for functional plasticity since the loss of vision that results from deprivation does not reliably correlate in timing or extent with ocular dominance shifts away from the amblyopic eye.

\section{Normal development}

A natural extension of the results from the early studies on visual cortical plasticity is that the normal development of vision would be limited by development of the visual cortex. Vision is quite poor in infant primates compared to adults. The notion was that the development of visual cortex would explain the developmental time course for vision. However, it is now clear that this idea is too simplistic and not supported by behavioral, physiological, and anatomical developmental data. For example, visual acuity, or spatial 
resolution, is the canonical descriptor of vision and visual development. A direct comparison of acuity development with development of potential limiting factors at the level of retinal photoreceptors, LGN, and primary visual cortex demonstrated that these factors do not set an important limit on visual acuity and contrast sensitivity development either alone or in aggregate (Kiorpes et al., 2003; Kiorpes \& Movshon, 2004a; Movshon et al., 2005).

The time course for acuity development in macaque and human infants is shown in Fig. 2A; acuity develops to adult levels over the first 9 months after birth in monkeys and 5 years after birth in humans (Teller, 1997). An ideal observer analyses of spatial contrast sensitivity development in macaques showed that the early visual system was significantly more mature in infants than behaviorally measured vision (Kiorpes et al., 2003). Moreover, nearly all aspects of V1 anatomical organization (Horton \& Hocking, 1996; Blasdel, Obermeyer \& Kiorpes, 1995; Coogan \& Van Essen, 1996; Callaway, 1998; Batardiere et al., 2002; Kennedy \& Burkhalter, 2004; Baldwin et al, 2012) and most physiological properties (Wiesel \& Hubel, 1974; Chino et al., 1997; Kiorpes \& Movshon, 2004a; Zhang et al., 2005; 2008; Zheng et al., 2007; Maruko et al., 2008) are already adult-like near birth or within about 8 weeks thereafter in macaques suggesting that the development seen behaviorally is not subserved by development of basic receptive field properties of neurons in V1. One exception to the adult-like organization appears to be feedback connectivity, which continues to reorganize up to about 4 months of age (Kennedy \& Burkhalter, 2004). The few studies of neural response properties in the first extrastriate visual area, V2, have also shown a relatively mature state at the next level on from V1 (Zhang et al., 2005; 2013; Zheng et al., 2007, Maruko et al., 2008) although V2 lags behind V1 on some measures. These studies disagree regarding the rate of maturation of some receptive field properties, such as centersurround balance in V2, which may require a more extended developmental period (Zhang et al., 2005; 2013). In aggregate, these data suggest that the visual system, at least up through area V1 and likely also through V2, is remarkably mature compared to behavioral performance. A summary figure (Fig. 2B) shows the relative development of acuity for pigtailed macaques plotted with the development of spatial resolution at each level of the early visual system hierarchy from the retina through V2. Several points are illustrated by this summary: first, acuity improves by about a factor of 30 from near birth until adult levels of acuity are reached, while the neural metrics change by only a factor of 2-3 regardless of level; second, these visual system properties are substantially more mature near birth than is visual function; third, the rate of change of resolution at cortical levels of the visual system is largely dictated by that defined by photoreceptor spacing in the retina. We can conclude that the functional and anatomical organization of early visual cortex does not set important limits on the development of visual spatial resolution. In contrast, temporal resolution, as measured by flicker sensitivity, appears to be constrained by early development at the level of the LGN or before (Stavros \& Kiorpes, 2008).

As noted above, another important consideration is that different functions develop over quite different extents and time courses (e.g., Kiorpes \& Movshon, 1989; Harwerth et al., 1990; Kiorpes, 1992; Kiorpes \& Bassin, 2003; Kiorpes et al., 2012). There are many aspects of visual function besides basic spatial resolution and contrast sensitivity, each of which is described by its own developmental time course and characteristic degree of postnatal maturation. For example, another measure of spatial acuity, Vernier acuity (positional 
resolution), develops over a time course somewhat longer than spatial resolution and contrast sensitivity but improves to a greater extent: by about factor of 100 . Yet other visual abilities are not measureable near birth and only begin to develop at older ages, often showing a slow, steady developmental time course that may continue to improve over years. Some notable examples come from higher-order, or "global", form vision tasks such as contour integration - the ability to link elements over space to form a percept of extended contours - and Glass pattern perception - the ability to appreciate the structure in displays based on the global orientation of dot pairs - which in macaques do not appear until 3-4 months after birth and improve well beyond the first postnatal year (Kiorpes \& Bassin, 2003; Kiorpes et al., 2012). Figure 3 compares the developmental time courses for four representative visual functions, two that are considered basic and are measurable near birth, spatial contrast sensitivity and Vernier acuity (Fig. 3A,B), and two that are not onset until 10-20 weeks after birth, global form discrimination and contour integration (Fig. 3C,D). Interestingly, in the case of Vernier acuity, while its onset is very early it does not reach asymptotic levels until much later than contrast sensitivity, continuing development well into the second postnatal year.

Clearly these different developmental profiles cannot all be explained by the same process. It is conceivable that they could all depend on changes at the same level of visual cortex by reflecting different aspects of neural organization, different receptive field properties, or population level interactions among neurons (Parker \& Hawken, 1985). However, given the mature state of V1 near birth in primate infants, it is likely that some critical limitations on visual development lie downstream from V1. In particular, stereopsis and global visual functions - those that require integration of information across space or space-time - have been linked to neural processing in areas V2 and beyond. There is evidence that some global functions rely on different principles of neural organization than those observed with the single unit neurophysiology discussed thus far. We next consider some illustrative examples and alternative ideas.

Stereopsis is our ability to appreciate distance and depth based on disparity - differences in location of an image on the two retinae. A common measure of this ability is stereoacuity. Stereoacuity follows a very different developmental profile than most other types of acuity. In macaques, stereoacuity shows a rather abrupt onset at $4-6$ weeks after birth with an initial rapid development over the succeeding $4-8$ weeks to reach a plateau (O'Dell and Boothe, 1997). In humans, this ability is onset at $4-6$ months (Birch, 1993), quickly reaches a plateau, but then is followed by a longer slower period of development to adult levels that continues well into school age, changing overall by about a factor of 1000 (Giaschi et al., 2013). This profile seems to be somewhat more compressed in macaques with asymptotic levels reached by 3 months. Chino and colleagues measured disparity sensitivity of neurons in V1 and V2 in infant monkeys in attempt to capture the neural correlates of this abrupt rapid developmental profile. Interestingly, binocularity is well established at the earliest ages recorded ( 2 weeks) and adult-like binocular interactions were found already at those early ages (Chino et al., 1997; Maruko et al., 2008). However, Maruko et al. (2008) were able to model the behavioral stereoacuity development profile by taking account of a constellation of measures including the coarser spatial resolution of infant neurons and their lower response rates (see below). The correlation between V2 
disparity acuity based on this model and the behavioral data on stereoacuity development in macaques (O'Dell \& Boothe, 1997) is impressive. This comparison is reproduced in Figure 4: the profiles represented by the open circles (perception) and the filled squares (V2 neurons) (from Maruko et al., 2008).

The middle temporal area, MT/V5, in the dorsal stream is well-known to be involved in the processing of global motion stimuli and provides signals that support the perception of motion (Britten et al., 1992; Newsome \& Pare, 1988; Rudolph \& Pasternak, 1999; Salzman et al., 1992). Naturally, one might expect a close relationship between the development of neural activity in MT and development of motion sensitivity. Behavioral development of motion sensitivity has been described in infant macaques using random dot kinematogram stimuli (RDKs) as well as drifting grating and plaid patterns (Mikami \& Fujita, 1992; Kiorpes \& Movshon, 2004b; Hall-Haro \& Kiorpes, 2008; Kiorpes et al., 2012). Infant macaques are able to detect visual motion and discriminate its direction soon after birth, although sensitivity is substantially reduced compared with that in adults and improves over a time course that extends over at least the first 2 years after birth (Kiorpes \& Movshon, 2004b; Kiorpes et al., 2012). Interestingly, the perception of 2-D pattern motion follows a different developmental profile: perception of coherent motion of a plaid pattern (composed of 2 orthogonal drifting grating patterns) develops comparatively late. Infants under the age of 12 weeks failed to identify the direction of plaid motion while they had no difficulty discriminating the direction of simple, 1-D grating motion on a comparable task (Hall-Haro \& Kiorpes, 2008). Furthermore, pattern motion sensitivity reached asymptotic levels around the end of the first postnatal year, earlier than global motion sensitivity measured with RDKs. Figure 5 compares developmental time courses for an RDK motion discrimination (Fig. 5A) and a plaid direction discrimination (Fig. 5B). Two principles are revealed by these data sets. First, the developmental time course for motion perception depends on the type of motion stimuli used and the task used to measure the ability (see also, Parrish et al., 2005), and second, the neural processes supporting perception of motion in RDKs and plaids are not necessarily the same despite the fact that both involve motion integration and have been demonstrated to correlate with the function of neurons in area MT (Movshon et al., 1985; Rodman \& Albright, 1989). It is quite possible that simple 1-D motion detection or discrimination (as with grating stimuli) depends on direction selective elements in V1, while motion integration (as with RDK stimuli) or complex pattern motion sensitivity depend on the function of different subsets of higher-order motion-sensitive cells in MT.

Direct comparison of behavioral and neural development of motion sensitivity was undertaken by Kiorpes, Movshon and colleagues (see Kiorpes \& Movshon, 2014). They recorded single-neuron response properties in area MT of infants aged 1 to 16 weeks as well as in adults and found infant neurons to be well-tuned for speed and direction of gratings and RDK motion similarly to those in adults. This finding suggests that the substrate for directional global motion discrimination is present in newborn MT, but the adult-like tuning is surprising given the immaturity of RDK motion sensitivity in infants. It is reasonable to propose that the existence of this mature tuning enables the young animals to use global motion information to perform the discrimination but that some other aspect of neural development is required for achieving adult-like sensitivity. One striking difference that was found between infant and adult MT was a near absence of pattern direction selective (PDS) 
neurons, those that signal the direction of motion of complex patterns, such as plaid patterns (Movshon et al., 1985; Rodman \& Albright, 1989). The proportion of PDS cells encountered was extremely low in the infants; even at 16 weeks it was only one-half that of adults: $20 \%$ compared to $40 \%$. PDS responses emerge from the elaboration of specific feedforward projections from V1 to MT (Rust et al., 2006), and the late development of these cells may reflect the delayed refinement of that pattern of connections. These neural data suggest that delayed development of pattern motion discrimination may be due to reduced representation of PDS cells in MT, and that the subsequent development to adult levels of plaid motion sensitivity may be defined by the refinement of these connections to achieve a full complement of these neurons.

The behavioral data showing early onset of RDK motion discrimination correlates nicely with the neural data showing that the machinery to detect and discriminate global motion is present essentially at birth, but leaves open the question of what explains the comparatively poor performance of infants and the extended developmental profile. Although the tuning properties of most infant neurons appear to be adult-like at very young ages, they respond at quite low rates and with long latency. The weaker responses could translate to lower signalto-noise ratio in infants or to greater response variability. If so, changes in these properties might be critical to the development of sensitivity as opposed to limiting the initial onset of perceptual discrimination capability.

There is evidence that the infant visual system is "noisier" than that of the adult and that developmental changes in contrast sensitivity parallel a decrease in signal-to-noise ratio measured psychophysically, which may reflect improved signaling by cortical neurons (Brown, 1994; Kiorpes \& Movshon, 1998; Kiorpes et al., 2003; Norcia, 2004). As we found in MT, nearly every study of neural activity patterns in infant primate geniculostriate and extrastriate visual pathways remarks upon the weak responses of infant neurons (Rodman et al., 1993; Chino et al., 1997; Hawken et al., 1997; Kiorpes \& Movshon, 2004a; 2014; Movshon et al., 2005; Zheng et al., 2007; Maruko et al., 2008; Zhang et al., 2008; 2013); in cortical visual areas there is also a remarkably long response latency. Overall responsiveness changes with age but it does so with a somewhat different profile depending on the visual area, and in some cases layer or cell type (Hawken et al., 1997; Maruko et al., 2008), with structures early in the visual pathway generally becoming adult-like earlier than those further along in extrastriate cortex. On the other hand, an analysis of the reliability of infant V1 neuronal firing concluded that in fact their responses are more reliable, not less so, despite being weaker (Rust, Schultz, \& Movshon, 2002). Also, infant MT neurons show lower variability in that the variance-to-mean ratio is closer to 1 in infants than in adults where it is typically around 2 (Kiorpes, unpublished data); a similar result has been reported for area V2 (Maruko et al., 2008). Thus, the overall lower response rates seen in infant neurons could help to explain postnatal development of sensitivity to weak stimuli while reliability of neural firing is not likely to be a factor.

The discussion thus far has focused on single-unit properties of neurons, as the field has traditionally thought of the relationship between behavior and its neural substrates as depending on the properties of neuronal receptive fields in a given visual area (Barlow, 1972; 2009) or activity patterns in a particular set of neurons (Teller, 1984). However, as we 
have seen with respect to development, single neuron properties in areas thought to be important for a given behavioral capability in many cases do not appear to define the development of that ability, which suggests that some other process or set of neurons limits behavior in that case. It is useful to consider that the brain has 100 billion neurons for a reason and that perhaps one reason is that many neurons - within and across brain areas act together to represent the sensory input and direct the motor output. Therefore, it may be more useful to model the "population response" from a given brain area or from a collection of areas to look for a link to behavior. The population output from one brain area to the next will depend not only on the maturity of the receptive field properties of single neurons but also on their responsiveness compared to background, the cohesiveness of their temporal response properties (e.g., latency), and correlations among neurons in the population. A basic pooling model of the population output from MT in infants was reasonably successful at representing the development of sensitivity to direction information in RDK motion (see Kiorpes \& Movshon, 2014), suggesting that this approach is a fruitful way forward. Moreover, as there are multiple levels of the visual hierarchy, each level feeding back as well as forward (Felleman \& Van Essen, 1991), and it is unclear how this hierarchical organization matures (Guillery, 2005), it is important to consider the ability of downstream areas to 'decode' - or interpret - the information it receives. It is unlikely that a single downstream 'black-box decoder' or unified decision process prior to the behavioral output itself provides a critical limitation on behaviorally measured visual functions because of the many different developmental profiles shown by different visual functions. If such a process were to act as a bottleneck, we would expect at the least to see sensitivity reaching adult levels at a similar age regardless of the type of visual ability or limitations on its onset. Whatever the case, nothing is currently known about the development of any such population characteristics or decoding processes.

Finally, it is unclear which of the many aspects of development reviewed herein relates to "the critical period". It is clear that there are multiple critical periods in terms of anatomy and physiology, but what defines the critical period for visual function? In a thoughtful perspective piece, Daw (1998) points out that in fact there are multiple critical periods for function as well, with different sensitive periods for normal development of vision, its disruption by abnormal visual experience, and its restoration following treatment. Recent research into the neural mechanisms underlying the critical period in rodents have identified changes in excitatory-inhibitory balance in neural circuits as well as specific changes in levels of neuromodulators as important arbiters of critical period timing and cortical plasticity (for reviews, see Bavalier et al., 2010; Baroncelli, Maffei \& Sale, 2011; Sur et al., 2013; Takesian \& Hensch, 2013). New studies of neural and behavioral development with a focus on modeling of circuit level changes and population read-out will be required to address this complex question.

\section{Acknowledgements}

The research described was supported by NIH grant EY05864 to L. Kiorpes, EY0217 to JA Movshon, and RR00166 to the Washington National Primate Center. 


\section{References}

Baldwin MK, Kaskan PM, Zhang B, Chino YM, Kaas JH. Cortical and subcortical connections of V1 and V2 in early postnatal macaque monkeys. J Comp Neurol. 2012; 520:544-569. [PubMed: 21800316]

Barlow HB. Single units and sensation: a neuron doctrine for perceptual psychology? Perception. 1972; 1:371-394. [PubMed: 4377168]

Barlow HB. Single units and sensation: a neuron doctrine for perceptual psychology? Perception. 2009; 38(6):795-798. [PubMed: 19806956]

Baroncelli L, Maffei L, Sale A. New perspectives in amblyopia therapy on adults: a critical role for the excitatory/inhibitory balance. Front Cell Neurosci. 2011; 5:25. [PubMed: 22144947]

Batardière A, Barone P, Knoblauch K, Giroud P, Berland M, Dumas AM, Kennedy H. Early specification of the hierarchical organization of visual cortical areas in the macaque monkey. Cereb Cortex. 2002; 12:453-465. [PubMed: 11950763]

Bavalier D, Levi DM, Li RW, Dan Y, Hensch TK. Removing brakes on adult brain plasticity: From molecular to behavioral interventions. J Neurosci. 2010; 30:14964-14971. [PubMed: 21068299]

Bi H, Zhang B, Tao X, Harwerth RS, Smith EL 3rd, Chino YM. Neuronal responses in visual area V2 (V2) of macaque monkeys with strabismic amblyopia. Cereb Cortex. 2011; 2:2033-2045. [PubMed: 21263036]

Birch, EE. Stereopsis in infants and its developmental relation to visual acuity. In: Simons, K., editor. Early Visual Development, Normal and Abnormal. Oxford: Oxford University Press; 1993. p. 224-235.

Blakemore C, Vital-Durand F. Effects of visual deprivation on the development of the monkey's lateral geniculate nucleus. J Physiol Lond. 1986; 380:493-511. [PubMed: 3112372]

Blasdel G, Obermayer K, Kiorpes L. Organization of ocular dominance and orientation columns in the striate cortex of neonatal macaque monkeys. Vis Neurosci. 1995; 12:589-603. [PubMed: 7654611]

Britten KH, Shadlen MN, Newsome WT, Movshon JA. The analysis of visual motion: a comparison of neuronal and psychophysical performance. J Neurosci. 1992; 12:4745-4765. [PubMed: 1464765]

Brown AM. Intrinsic contrast noise and infant visual contrast discrimination. Vis Res. 1994; 34:19471964. [PubMed: 7941396]

Callaway EM. Prenatal development of layer-specific local cortical circuits in primary visual cortex of the macaque monkey. J Neurosci. 1998; 18:1505-1527. [PubMed: 9454858]

Chino YM, Smith EL 3rd, Hatta S, Cheng H. Postnatal development of binocular disparity sensitivity in neurons of the primate visual cortex. J Neurosci. 1997; 17:296-307. [PubMed: 8987756]

Coogan TA, Van Essen DC. Development of connections within and between areas V1 and V2 of macaque monkeys. J Comp Neurol. 1996; 372:327-342. [PubMed: 8873864]

Daw NW. Critical periods and amblyopia. Arch Ophthalmol. 1998; 116:502-505. [PubMed: 9565050]

Felleman DJ, Van Essen DC. Distributed hierarchical processing in the primate cerebral cortex. Cereb Cortex. 1991; 1:1-47. [PubMed: 1822724]

Giaschi D, Narasimhan S, Solski A, Harrison E, Wilcox LM. On the typical development of stereopsis: fine and coarse processing. Vis Res. 2013; 89:65-71. [PubMed: 23891704]

Guillery RW. Is postnatal neocortical maturation hierarchical? Trends Neurosci. 2005; 28:512-517. [PubMed: 16126285]

Hall-Haro C, Kiorpes L. Normal development of pattern motion sensitivity in macaque monkeys. Vis Neurosci. 2008; 25:675-684. [PubMed: 18976542]

Harwerth RS, Smith EL 3rd, Crawford ML, Noorden GK. Behavioral studies of the sensitive periods of development of visual functions in monkeys. Behav Brain Res. 1990; 41:179-198. [PubMed: 2288671]

Harwerth RS, Smith EL 3rd, Duncan GC, Crawford ML, Noorden GK. Multiple sensitive periods in the development of the primate visual system. Science. 1986; 232:235-238. [PubMed: 3952507]

Dev Neurobiol. Author manuscript; available in PMC 2016 October 01. 
Hawken MJ, Blakemore C, Morley JW. Development of contrast sensitivity and temporal-frequency selectivity in primate lateral geniculate nucleus. Exp Brain Res. 1997; 114:86-98. [PubMed: 9125454]

Headon MP, Sloper JJ, Hiorns RW, Powell TP. Cell size changes in undeprived laminae of monkey lateral geniculate nucleus after monocular closure. Nature. 1979; 281:572-574. [PubMed: 114861]

Hendrickson AE, Movshon JA, Eggers HM, Gizzi MS, Boothe RG, Kiorpes L. Effects of early unilateral blur on the macaque's visual system. II. Anatomical observations. J Neurosci. 1987; 7:1327-1339. [PubMed: 3033169]

Horton JC, Hocking DR. An adult-like pattern of ocular dominance columns in striate cortex of newborn monkeys prior to visual experience. J Neurosci. 1996; 16:1791-1807. [PubMed: 8774447]

Horton JC, Hocking DR. Timing of the critical period for plasticity of ocular dominance columns in macaque striate cortex. J Neurosci. 1997; 17:3684-3709. [PubMed: 9133391]

Hubel DH, Wiesel TN, LeVay S. Plasticity of ocular dominance columns in monkey striate cortex. Phil Trans Roy Soc Lond B. 1977; 278:377-409. [PubMed: 19791]

Kennedy, H.; Burkhalter, A. Ontogenesis of cortical connectivity. In: Chalupa, LM.; Werner, JS., editors. The Visual Neurosciences. Cambridge: MIT Press; 2004. p. 146-158.

Kiorpes L. Development of Vernier acuity and grating acuity in normally reared monkeys. Vis Neurosci. 1992; 3:243-251. [PubMed: 1390384]

Kiorpes L, Boothe RG, Hendrickson AE, Movshon JA, Eggers HM, Gizzi MS. Effects of early unilateral blur on the macaque's visual system. I. Behavioral observations. J Neurosci. 1987; 7:1318-1326. [PubMed: 3572483]

Kiorpes L, Movshon JA. Differential development of two visual functions in primates. Proc Natl Acad Sci USA. 1989; 86:8998-9001. [PubMed: 2813434]

Kiorpes L, Kiper DC, O'Keefe LP, Cavanaugh JR, Movshon JA. Neuronal correlates of amblyopia in the visual cortex of macaque monkeys with experimental strabismus and anisometropia. $\mathrm{J}$ Neurosci. 1998; 18:6411-6424. [PubMed: 9698332]

Kiorpes L, Movshon JA. Peripheral and central factors limiting the development of contrast sensitivity in macaque monkeys. Vis Res. 1998; 38:61-70. [PubMed: 9474376]

Kiorpes L, Bassin SA. Development of contour integration in macaque monkeys. Vis Neurosci. 2003; 20:567-575. [PubMed: 14977335]

Kiorpes L, Tang C, Hawken MJ, Movshon JA. Ideal observer analysis of the development of spatial contrast sensitivity in macaque monkeys. J Vis. 2003; 3:630-641. [PubMed: 14640887]

Kiorpes, L.; Movshon, JA. Neural limitations on visual development in primates. In: Chalupa, LM.; Werner, JS., editors. The Visual Neurosciences. Cambridge: MIT Press; 2004. p. 159-173.

Kiorpes L, Movshon JA. Development of sensitivity to visual motion in macaque monkeys. Vis Neurosci. 2004; 21:851-859. [PubMed: 15733340]

Kiorpes L, Price T, Hall-Haro C, Movshon JA. Development of sensitivity to global form and motion in macaque monkeys (Macaca nemestrina). Vis Res. 2012; 63:34-42. [PubMed: 22580018]

Kiorpes, L.; Movshon, JA. Neural limitations on visual development in primates: Beyond striate cortex. In: Werner, J.; Chalupa, L., editors. The New Visual Neurosciences. Cambridge: MIT Press; 2014. p. 1423-1431.

Kozma P, Kiorpes L. Contour integration in amblyopic monkeys. Vis Neurosci. 2003; 20:577-588. [PubMed: 14977336]

LeVay S, Wiesel TN, Hubel DH. The development of ocular dominance columns in normal and visually deprived monkeys. J Comp Neurol. 1980; 191:1-51. [PubMed: 6772696]

Levitt JB, Schumer RA, Sherman SM, Spear PD, Movshon JA. Visual response properties of neurons in the LGN of normally reared and visually deprived macaque monkeys. J Neurophysiol. 2001; 85:2111-2129. [PubMed: 11353027]

Lewis TL, Maurer D. Multiple sensitive periods in human visual development: evidence from visually deprived children. Dev Psychobiol. 2005; 46:163-183. [PubMed: 15772974]

Dev Neurobiol. Author manuscript; available in PMC 2016 October 01. 
Maruko I, Zhang B, Tao X, Tong J, Smith EL 3rd, Chino YM. Postnatal development of disparity sensitivity in visual area 2 (v2) of macaque monkeys. J Neurophysiol. 2008; 100:2486-2495. [PubMed: 18753321]

Mayer DL, Dobson V. Visual acuity development in infants and young children, as assessed by operant preferential looking. Vis Res. 1982; 22:1141-1151. [PubMed: 7147725]

Mikami A, Fujita K. Development of the ability to detect visual motion in infant macaque monkeys. Dev Psychobiol. 1992; 25:345-354. [PubMed: 1526322]

Movshon JA, Eggers HM, Gizzi MS, Hendrickson AE, Kiorpes L, Boothe RG. Effects of early unilateral blur on the macaque's visual system. III. Physiological observations. J Neurosci. 1987; 7:1340-1351. [PubMed: 3572484]

Movshon, JA.; Kiorpes, L. The role of experience in visual development. In: Coleman, JR., editor. Development of Sensory Systems in Mammals. New York: John Wiley \& Sons; 1990. p. 155-202.

Movshon, JA.; Adelson, EH.; Gizzi, MS.; Newsome, WT. The analysis of moving visual patterns. In: Chagas, C.; Gattass, R.; Gross, C., editors. Pattern Recognition Mechanisms. Rome: Vatican Press; 1985. p. 117-151.

Movshon JA, Kiorpes L, Hawken MA, Cavanaugh JR. Functional maturation of the macaque's lateral geniculate nucleus. J Neurosci. 2005; 25:2712-2722. [PubMed: 15758181]

Newsome WT, Pare EB. A selective impairment of motion perception following lesions of the middle temporal visual area (MT). J Neurosci. 1988; 8:2201-2211. [PubMed: 3385495]

Norcia, AM. Development of spatial selectivity and response timing in humans. In: Werner, J.; Chalupa, L., editors. The New Visual Neurosciences. Cambridge: MIT Press; 2004. p. 174-188.

O'Dell C, Boothe RG. The development of stereoacuity in infant rhesus monkeys. Vis Res. 1997; 37:2675-2684. [PubMed: 9373667]

Parker A, Hawken M. Capabilities of monkey cortical cells in spatial-resolution tasks. J Opt Soc Am A. 1985; 2:1101-1114. [PubMed: 3926970]

Parrish EE, Giaschi DE, Boden C, Dougherty R. The maturation of form and motion perception in school age children. Vis Res. 2005; 45:827-837. [PubMed: 15644223]

Rodman HR, Albright TD. Single-unit analysis of pattern-motion selective properties in the middle temporal visual area (MT). Exp Brain Res. 1989; 75:53-64. [PubMed: 2707356]

Rodman HR, Scalaidhe SP, Gross CG. Response properties of neurons in temporal cortical visual areas of infant monkeys. J of Neurophysio. 1993; 70:1115-1136.

Rudolph K, Pasternak T. Transient and permanent deficits in motion perception after lesions of cortical areas MT and MST in the macaque monkey. Cereb Cortex. 1999; 9(1):90-100. [PubMed: 10022498]

Rust NC, Mante V, Simoncelli EP, Movshon JA. How MT cells analyze the motion of visual patterns. Nat Neurosci. 2006; 9:1421-1431. [PubMed: 17041595]

Rust NC, Schultz SR, Movshon JA. A reciprocal relationship between reliability and responsiveness in developing visual cortical neurons. J Neurosci. 2002; 22:10519-10523. [PubMed: 12486142]

Sakai E, Bi H, Maruko I, Zhang B, Zheng J, Wensveen J, Harwerth RS, Smith EL 3rd, Chino YM. Cortical effects of brief daily periods of unrestricted vision during early monocular form deprivation. J Neurophysiol. 2006; 95:2856-2865. [PubMed: 16452254]

Salzman CD, Murasugi CM, Britten KH, Newsome WT. Microstimulation in visual area MT: effects on direction discrimination performance. J Neurosci. 1992; 12:2331-2355. [PubMed: 1607944]

Smith EL 3rd, Chino YM, Ni J, Cheng H, Crawford ML, Harwerth RS. Residual binocular interactions in the striate cortex of monkeys reared with abnormal binocular vision. J Neurophysiol. 1997; 78:1353-1362. [PubMed: 9310426]

Stavros KA, Kiorpes L. Behavioral measurement of temporal contrast sensitivity development in macaque monkeys (Macaca nemestrina). Vis Res. 2008; 48:1335-1344. [PubMed: 18406441]

Sur M, Nagakura I, Chen N, Sugihara H. Mechanisms of plasticity in the developing and adult visual cortex. Prog Brain Res. 2013; 207:243-254. [PubMed: 24309257]

Takesian AE, Hensch TK. Balancing plasticity/stability across brain development. Prog Brain Res. 2013; 207:3-34. [PubMed: 24309249]

Teller DY. Linking propositions. Vis Res. 1984; 24:1233-1246. [PubMed: 6395480]

Dev Neurobiol. Author manuscript; available in PMC 2016 October 01. 
Teller DY. First glances: the vision of infants, the Friedenwald lecture. Invest Ophthalmol Vis Sci. 1997; 38:2183-2203. [PubMed: 9344342]

Wiesel TN. Postnatal development of the visual cortex and the influence of environment. Nature. 1982; 299(5884):583-591. [PubMed: 6811951]

Wiesel TN, Hubel DH. Single-Cell Responses in Striate Cortex of Kittens Deprived of Vision in One Eye. J Neurophysiol. 1963; 26:1003-1017. [PubMed: 14084161]

Wiesel TN, Hubel DH. Comparison of the effects of unilateral and bilateral eye closure on cortical unit responses in kittens. J Neurophysiol. 1965; 28:1029-1040. [PubMed: 5883730]

Wiesel TN, Hubel DH. Ordered arrangement of orientation columns in monkeys lacking visual experience. J Comp Neurol. 1974; 158:307-318. [PubMed: 4215829]

Zhang B, Zheng J, Watanabe I, Maruko I, Bi H, Smith EL 3rd, Chino Y. Delayed maturation of receptive field center/surround mechanisms in V2. Proc Natl Acad Sci USA. 2005; 102:58625867. [PubMed: 15824308]

Zhang B, Smith EL 3rd, Chino YM. Postnatal development of onset transient responses in macaque V1 AND V2 neurons. J Neurophysiol. 2008; 100:1476-1487. [PubMed: 18579658]

Zhang B, Tao X, Shen G, Smith EL 3rd, Ohzawa I, Chino YM. Receptive-field subfields of V2 neurons in macaque monkeys are adult-like near birth. J Neurosci. 2013; 33:2639-2649. [PubMed: 23392691]

Zheng J, Zhang B, Bi H, Maruko I, Watanabe I, Nakatsuka C, Smith EL 3rd, Chino YM. Development of temporal response properties and contrast sensitivity of V1 and V2 neurons in macaque monkeys. J Neurophysio. 2007; 97:3905-3916. 

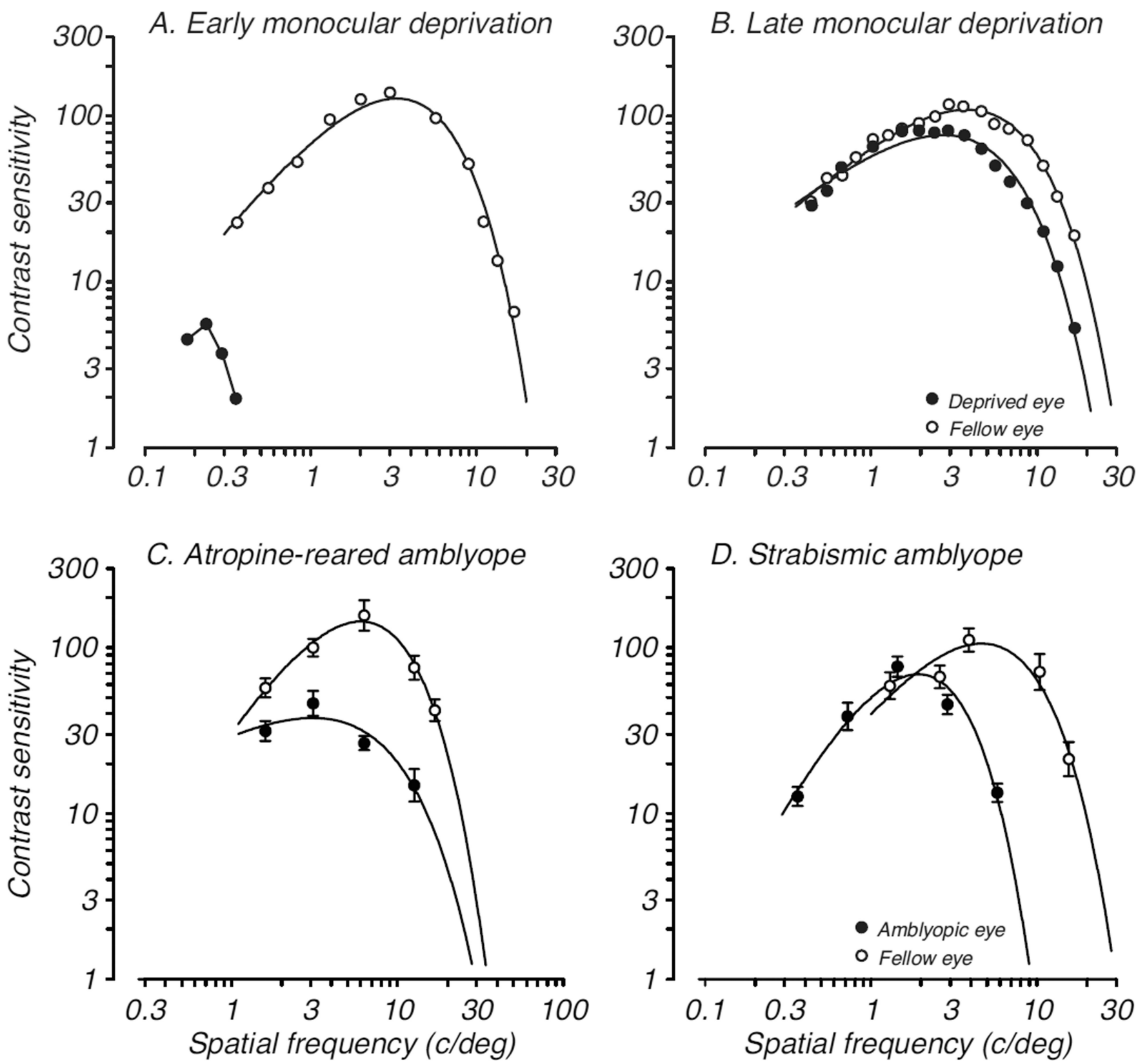

Figure 1.

Effects of abnormal visual experience during development on spatial vision in monkeys. Deficits in contrast sensitivity as a function of spatial frequency following: A. monocular deprivation by eyelid-suture for 18 months beginning at 4 months of age; B. monocular deprivation by eyelid-suture for 18 months beginning at 12 months of age; C. monocular chronic instillation of atropine for 7 months beginning at 2 weeks of age; D. esotropic strabismus created at 3 weeks of age. Open symbols represent fellow eye data; filled symbols represent amblyopic eye data. Data in A and B are from Harwerth et al., 1990, data in C are from Kiorpes et al., 1987; data in D are from Kozma \& Kiorpes, 2003. 

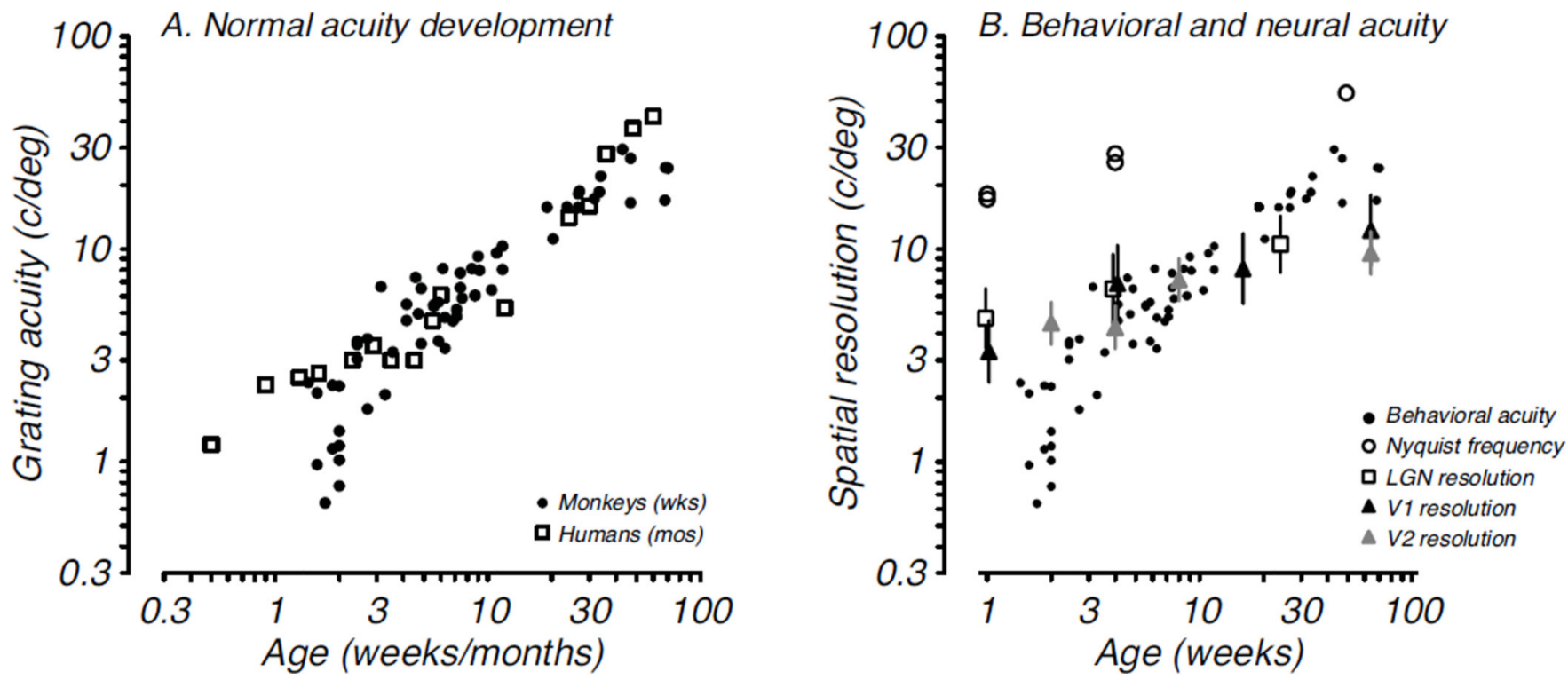

Figure 2. Behavioral and neural development of visual acuity

A. Grating acuity as measured behaviorally by preferential looking or operant methods is plotted as a function of age in weeks for monkeys (filled circles, Kiorpes, 1992) and in months for humans (open squares, Mayer and Dobson, 1982). B. Behavioral acuity data (from A, filled circles, monkeys) are plotted along with neural measures of acuity: nyquist frequency of the cone mosaic (open circles, Kiorpes et al., 2003), characteristic spatial frequency of parvocellular LGN neurons (open squares, Movshon et al., 2005), spatial resolution of V1 neurons (black triangles, Kiorpes \& Movshon, 2004a), and spatial resolution of V2 neurons (gray triangles, Maruko et al., 2008). 

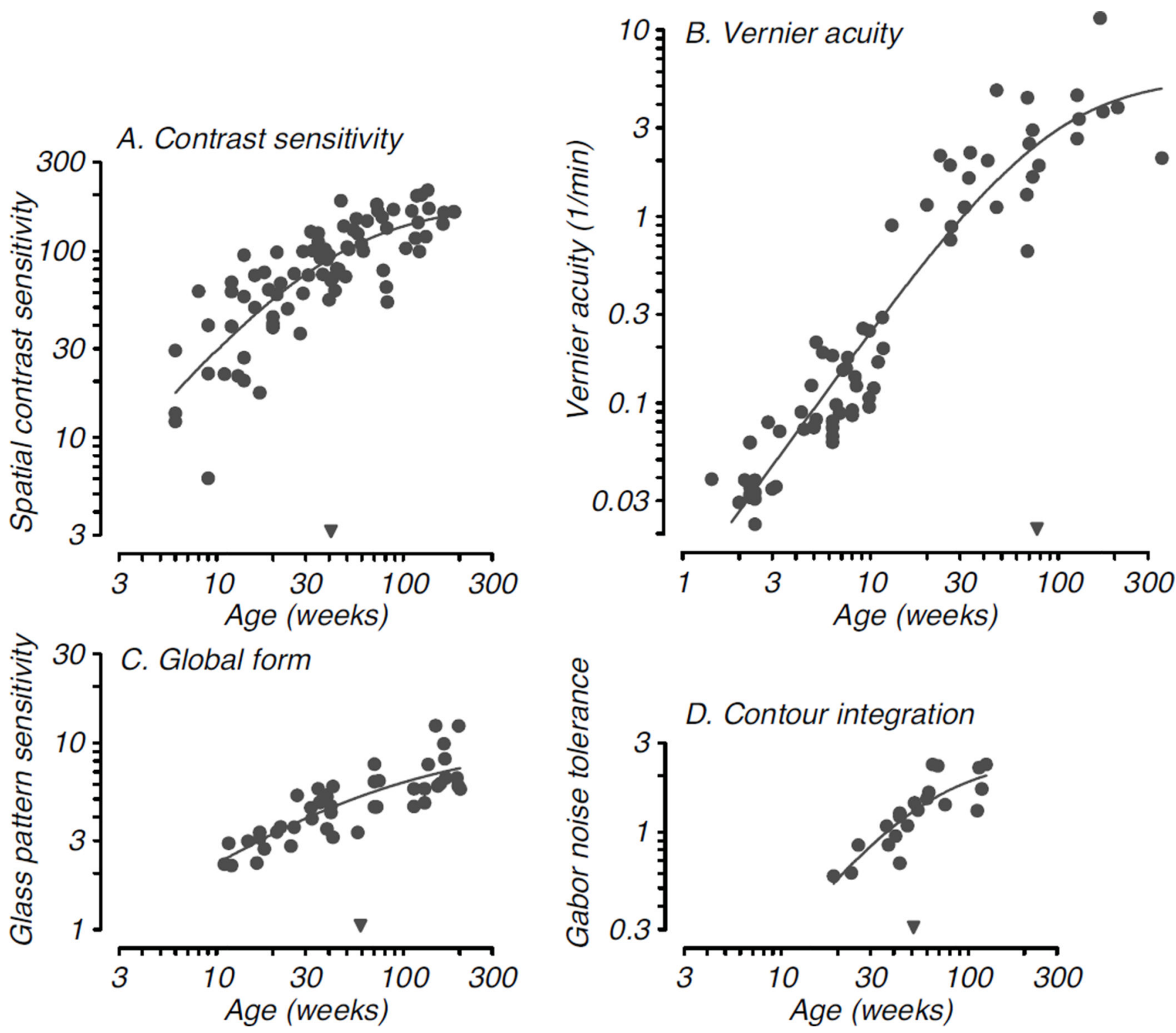

Figure 3. Developmental time course for four visual functions in monkeys

A. Sensitivity to spatial contrast as a function of age (Stavros \& Kiopres, 2008); B.

Development of ability to discriminate spatial positional offset, or Vernier acuity (Kiorpes, 1992, and unpublished data); C. Development of sensitivity to global structure in concentric Glass patterns (Kiorpes et al., 2012); D. Development of ability to link Gabor elements to form a coherent contour as a function of the density of background noise (Kiorpes \& Bassin, 2003). Smooth curves in each panel are Naka-Rushton functions fit to each dataset; the inverted filled triangles along the abscissa indicate the semi-saturation point for the functions, which provide a quantitative metric for the relative maturation of each visual function (see Stavros \& Kiorpes, 2008; Kiorpes et al., 2012). Note the relatively late maturation of Vernier acuity compared with the other spatial vision metrics. 


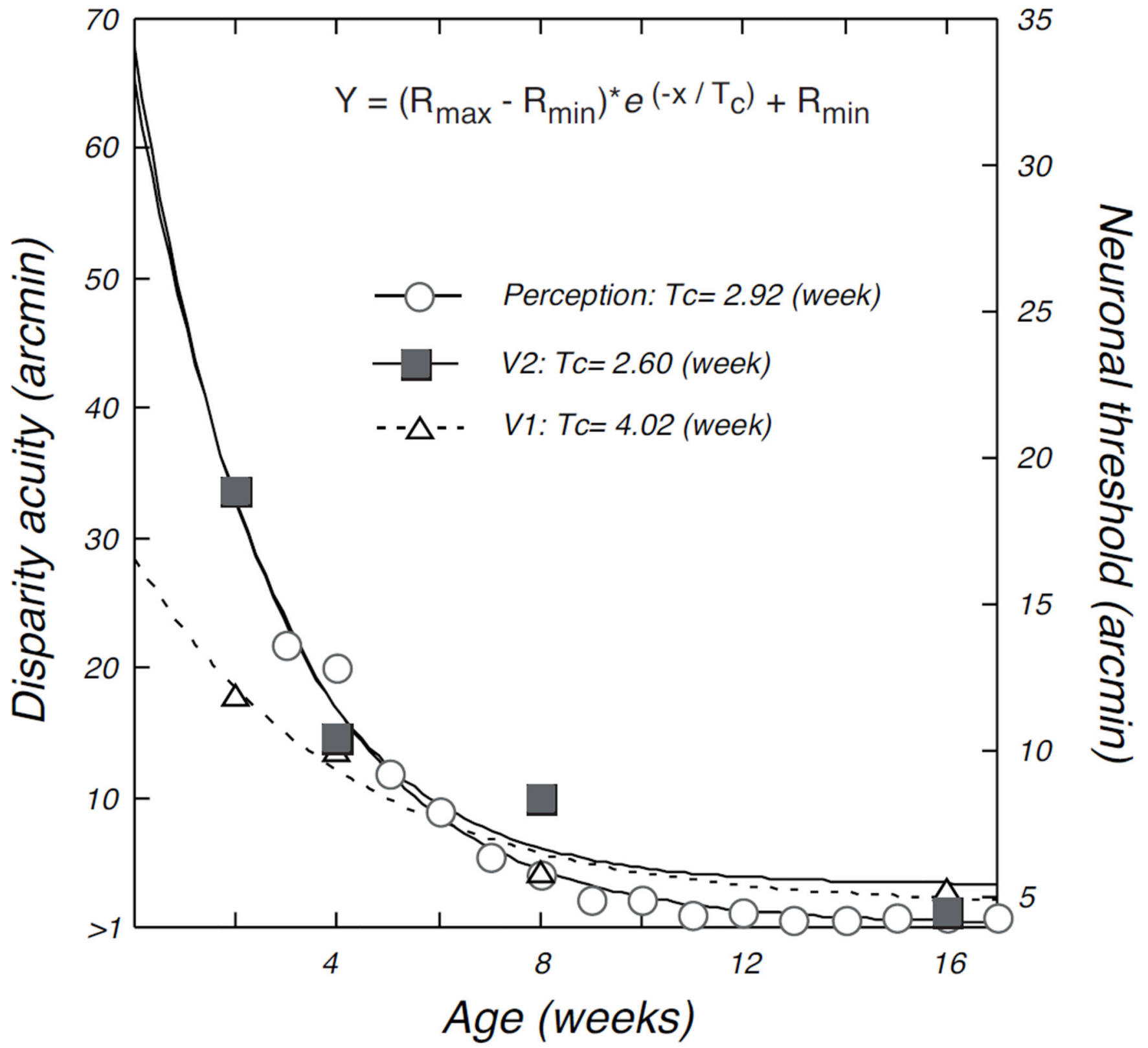

Figure 4.

Relative time course for improvement of disparity sensitivity of neurons in V1 and V2 and behavioral stereoacuity. Open circles show the development of stereoacuity measured behaviorally in infant macaques (from O'Dell \& Boothe, 1997); open triangles and filled squares plot disparity sensitivity of V1 and V2 neurons, respectively, as a function of age (from Maruko et al., 2008). Smooth curves are fitted exponential functions; Tc values are the time constants for each function, which provide a quantitative metric for comparison of the rate of maturation. The rate of maturation of disparity sensitivity in V2 was well matched to that of behavior. See Maruko et al. (2008) for details; reproduced with permission, YM Chino. 

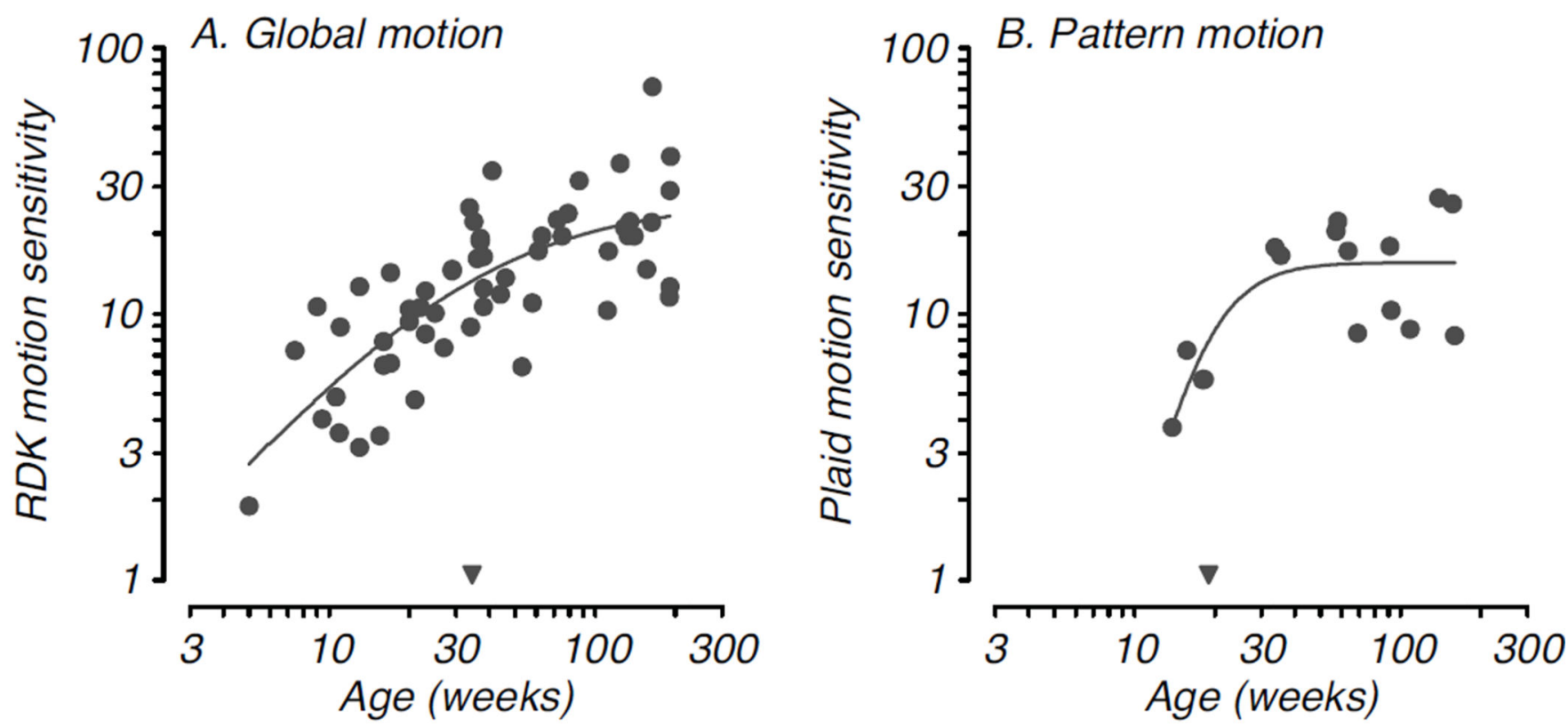

Figure 5. Developmental time course for two types of motion sensitivity

A. Sensitivity to global motion signals in translational random dot kinematograms is plotted as a function of age (Kiorpes et al., 2012). B. Development of the ability to discriminate the direction of motion of a complex plaid pattern plotted as a function of age (Hall-Haro \& Kiorpes, 2008). Smooth curves and inverted filled triangles as described in Fig. 3. Plaid motion sensitivity shows a later age of onset but earlier age at maturation than sensitivity to RDK motion. 